\title{
Dental Pulp Vascular Permeability Changes Induced by Dental Bleaching
}

\author{
Cristiane da Costa ${ }^{1}$, Sueli Patricia Harumi Miyagi ${ }^{1,2}$, Marcelo dos Santos $^{1}$, Manoel \\ Eduardo de Lima Machado ${ }^{1}$ and Márcia Martins Marques ${ }^{3 *}$ \\ ${ }^{I}$ Departamento de Endodontia; Faculdade de Odontologia; Universidade de São Paulo; São Paulo - SP - Brasil. \\ ${ }^{2}$ Faculdade de Odontologia; Universidade Braz Cubas; Mogi das Cruzes - SP - Brasil. ${ }^{3}$ Departamento de \\ Dentística; Faculdade de Odontologia; Universidade de São Paulo; São Paulo - SP - Brasil
}

\begin{abstract}
Aiming to compare the effect of different light sources for dental bleaching on vascular permeability of dental pulps, forty-eight incisors were used. The bleaching agent (35\% hydrogen peroxide) was activated by halogen light; LED (Light Emitting Diode) or LED, followed by laser phototherapy $(L P T)\left(\lambda=780 \mathrm{~nm} ; 3 \mathrm{~J} / \mathrm{cm}^{2}\right)$. After the bleaching procedures, the animals received an intra-arterial dye injection and one hour later were sacrificed. The teeth were diaphanized and photographed. The amount of blue stain content of each dental pulp was quantified using a computer imaging program. The data was statistically compared $(p \leq 0.05)$. The results showed a significant higher $(p \leq 0.01)$ dye content in the groups bleached with halogen light, compared with the control, LED and LED plus LPT groups. Thus, tooth bleaching activated by LED or LED plus LPT induces lesser resulted in increased vascular permeability than halogen light.
\end{abstract}

Key words: dental pulp, laser, LED, tooth bleaching, vascular permeability

\section{INTRODUCTION}

The concern with aesthetics has made tooth whitening is one of the most required procedures in the dental clinic. The tooth bleaching can be performed internally on nonvital teeth or externally on vital teeth. Hydrogen peroxide, sodium perborate, and cabamide peroxide are generally used for bleaching (Auschill et al. 2005; Zalkind et al. 1996). The application of light sources such as halogen light, LED (Light Emitting Diode) and lasers (Dederich and Bushick 2004; Stabholz et al. 2003) can increase the rate of bleaching agent degradation and the speed of the bleaching process. These procedures have high effectiveness in bleaching, but may have undesirable effects, such as change in tooth structure (Rotstein et al. 1996), external root resorption (Crim 1992), dental pulp inflammation (Bowles and Thompson, 1986; Robertson and Melfi 1980; Seale et al. 1981) and dentin sensitivity (Dahl and Pallesen 2003; Sulieman 2004).

High incidence of tooth sensitivity (from 67 to $78 \%$ ) has being reported after in-office bleaching with hydrogen peroxide in combination with heat (Nathanson and Parra 1987). Thus, heating along with penetration of bleaching agent into the dental pulp can trigger reversible inflammation (Robertson and Melfi 1980; Seale and Wilson 1985).

Phototherapy with low intensity laser (LPT) is used in various areas of biological sciences to promote the tissue regeneration of injured tissues.

\footnotetext{
*Author for correspondence: mmmarques@usp.br
} 
This therapy results in analgesic, antiinflammatory and biomodulatory effects (Ladarlado et al. 2004; Reddy 2004; Silveira et al. 2007). The laser light within the red visible and near infrared wavelengths corresponds to the energy absorption spectrum of the respiratory chain components, increasing the cellular metabolism of organisms under stress conditions (Robertson and Melfi 1980; Silveira et al. 2007). Moreover, the phototherapy with low intensity laser using infrared laser is able to compensate the cytotoxic effects of substances released by $35 \%$ hydrogen peroxide bleaching gel (Dantas et al. 2010).

Light sources are used for speeding the in-office dental bleaching and can cause tooth sensitivity probably due to reversible inflammation in the dental pulp. Knowing that LPT can modulate the inflammatory process, it would be interesting to analyze the effect of these light sources on the intrapulpal initial signs of inflammation after inoffice dental bleaching. Then, this study aimed to analyze the vascular permeability of dental pulps after in-office dental bleaching using different light sources.

\section{MATERIALS AND METHODS}

For the in vivo study, 12 adult male Wistar rats (Rattus norvegicus albinus) weighing an average of 180 to $200 \mathrm{~g}$ were used. All the animals were kept under constant temperature and with free access to food and water. The rats were anesthetized prior to the dental bleaching procedures using a mixture of $2 \%$ Xylazin (Roncum ${ }^{\circledR}$, Bayer do Brasil, SP, Brazil) and 5\% Ketamine (Ketalar®, Cristália, SP, Brazil) $(0.15$ $\mathrm{mL}$ per $100 \mathrm{~g}$ of rat bodyweight). Four incisors of each rat were used for the experiments. Thus, 48 incisors were divided into four experimental groups ( $\mathrm{n}=12$ per group), as follows:

1) Conventional method $(n=12)$ : Halogen light

2) LED $(n=12)$

3) LED plus LPT $(n=12)$

4) Control ( $n=12)$ : Non-treated

The bleaching procedures were performed using $35 \%$ hydrogen peroxide agent in 1,2 or 3 sessions, as shown in Table 1.

Table 1 - Distribution of the experimental groups in function of the sessions:

\begin{tabular}{|c|c|c|c|}
\hline Groups & 1 Session & 2 Sessions & 3 Sessions \\
\hline Conventional method & G1 $(n=4)$ & G4 $(n=4)$ & G7 $(n=4)$ \\
\hline (Halogen light) & 3 minutes & $\begin{array}{l}3 \text { minutes (each session) } \\
\text { with } 2 \text { days of interval }\end{array}$ & $\begin{array}{l}3 \text { minutes (each session) } \\
\text { with } 2 \text { days of interval }\end{array}$ \\
\hline LED & $\begin{array}{l}\mathrm{G} 2(\mathrm{n}=4) \\
3 \text { minutes }\end{array}$ & $\begin{array}{c}\text { G5 }(\mathrm{n}=4) \\
3 \text { minutes (each session) } \\
\text { with } 2 \text { days of interval }\end{array}$ & $\begin{array}{c}\mathrm{G} 8(\mathrm{n}=4) \\
3 \text { minutes (each session) } \\
\text { with } 2 \text { days of interval }\end{array}$ \\
\hline LED plus laser & $\begin{array}{c}\text { G3 }(n=4) \\
\text { LED + LPT }(3 \\
\text { seconds })\end{array}$ & $\begin{array}{c}\text { G6 }(\mathrm{n}=4) \\
\text { LED + LPT }(3 \text { seconds }) \\
\text { (each session) with } 2 \text { days of } \\
\text { interval }\end{array}$ & $\begin{array}{c}\text { G9 }(\mathrm{n}=4) \\
\text { LED + LPT (3 seconds) } \\
\text { (each session) with } 2 \text { days } \\
\text { of interval }\end{array}$ \\
\hline Control & \multicolumn{3}{|c|}{$\begin{array}{l}\mathrm{G} 10(\mathrm{n}=12) \\
\text { Non-treated: not submitted to the bleaching gels neither to the light sources }\end{array}$} \\
\hline
\end{tabular}

\section{Experiments}

The anesthetized animals were fixed on an operational table. Dental isolation and prophylaxis was performed previously to the bleaching process using $35 \%$ hydrogen peroxide associated to the different light sources tested. For the conventional treatment (G1, G4 and G7), a $600 \mathrm{~mW} / \mathrm{cm}^{2}$ halogen light (Dabi Atlante, Ribeirão Preto, SP, Brazil) was used for three minutes. For the LED group (G2, G5 and G8), a $470 \mathrm{~nm}$ LED, (Kondortech, São Carlos, SP, Brazil) was used for three minutes. The LPT after the LED application was performed at the groups LED plus LPT (G3, G6 and G9) using a GaAsAl diode laser at the wavelength of $780 \mathrm{~nm}$ and energy density of 3 $\mathrm{J} / \mathrm{cm}^{2}$, for three seconds. The time of bleaching was determined in a pilot study. Immediately after the last tooth bleaching session, the animals were submitted to the dye application as previously described (Duval-Araújo et al. 1994). Briefly, the dye $(0.6 \mathrm{ml}$ of Nankin ink) was injected in the rat blood circulation using the lateral caudal artery. 
After one hour, time enough for the complete excretion of the dye from the vascular system, the animals were sacrificed by anesthetic overdose and the jaw and the maxilla were removed.

The specimens were processed to obtain the diaphanized samples. Briefly, the samples were immersed into $2.5 \%$ sodium hypochlorite solution for seven days, followed for washing in running water for $24 \mathrm{~h}$. Then, the samples were immersed into $5 \%$ chloride acid solution for five days with daily change. After this procedure, they were washed in the running water for $24 \mathrm{~h}$ and then immersed into a crescent series of ethanol $(70,80$ and $96 \%$ ) during $24 \mathrm{~h}$ in each solution. At the end, they were immersed into methyl salicilate and the incisor crowns were removed.

After the diaphanization, the optical density of each crown was recorded using an imaging program (Imagelab 2000, São Paulo, SP, Brazil). This data indicated the amount of dye leaked from the vascular system that remained in the dental pulp tissue after the ink had been physiologically removed from the vascular system of the rats. Thus, this indirectly indicated the changes in the vascular permeability of the dental pulps of the teeth submitted or not to the bleaching procedures.

\section{Statistical analysis}

Each data point corresponded to the mean \pm SEM (standard error of the mean) of the optical densities of four teeth per experimental group. The data were compared by ANOVA complemented with the Tukey's test. The level of significance was defined as $5 \%(\mathrm{p} \leq 0.05)$.

\section{RESULTS}

The results are illustrated in Figure $1 \mathrm{~A}$ and represented in the graph of Figure 1B. The highest dye content values were observed in the group of dental bleaching using the conventional technique $(\mathrm{p}<0.01)$. The groups treated with LED and LED plus LPT presented similar amounts of dye.
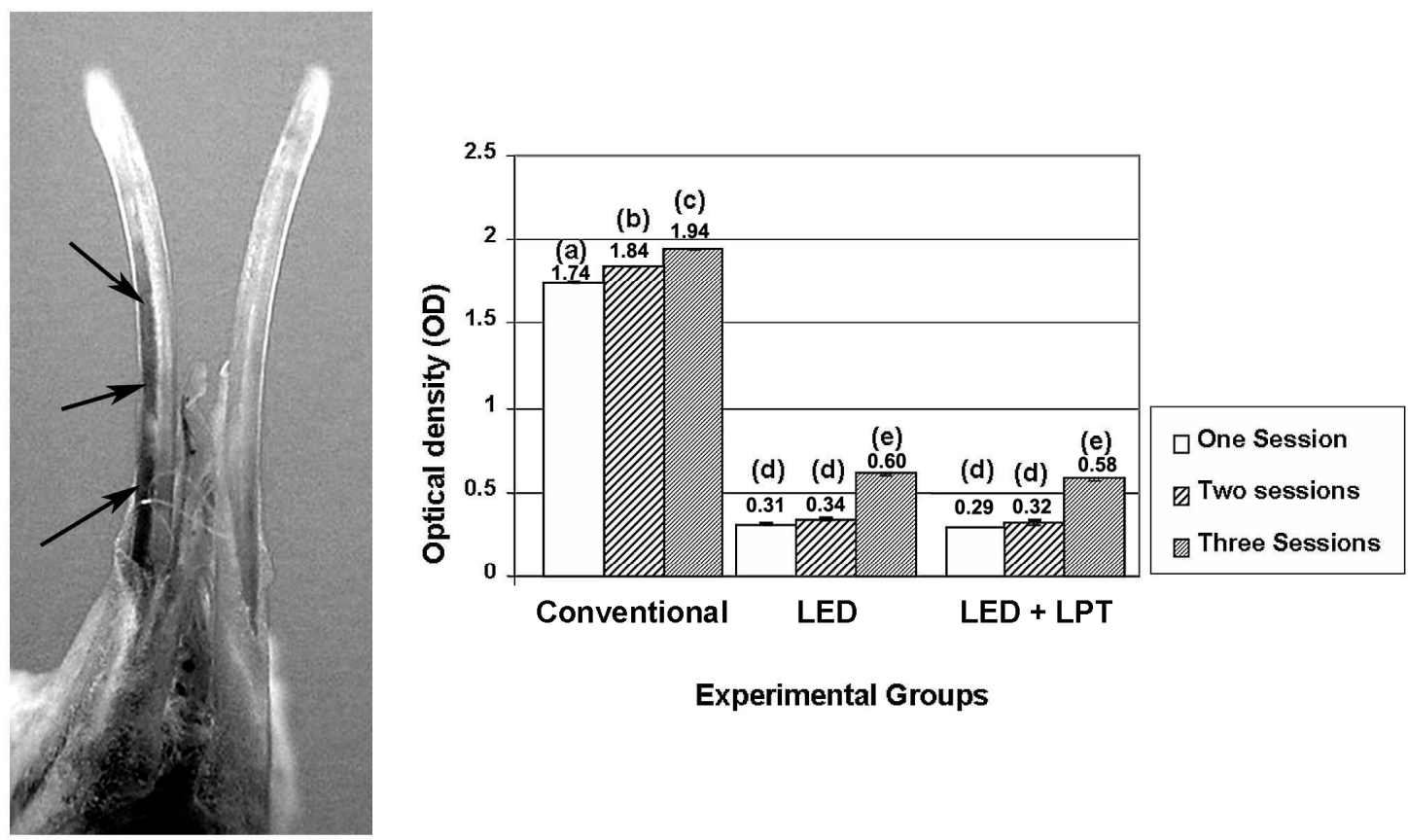

Experimental Groups

A

B

Figure 1 - Representation of the results on dental bleaching. (A): photograph of the rat jaw showing the experimental incisors after diaphanization. Observe the right incisor depicting a more stained dental pulp (arrows-conventional group). The left incisor with no staining belongs to the control group. (B) Graphic representation of the mean optical densities ( \pm standard error of the mean) of the diaphanized teeth of the different experimental groups. Different letters indicate statistical significant differences. 
Independently of the light sources applied during the dental bleaching, the amount of dye in the crowns was significantly higher in the samples bleached in the three sessions. In the group treated with the conventional bleaching procedure using the halogen light source, the dye increased proportionally in function of the number of bleaching sessions; however, when using LED and LED plus LPT, there was no difference between the data obtained after 1 and 2 sessions.

\section{DISCUSSION}

The undesirable side effects of in-office dental bleaching using the light sources for accelerating the dental bleaching process is still a matter of concern, especially due to the increased request of the general population for this dental procedure. The most common side effects of the in-office dental bleaching is tooth sensitivity, which could be due to the penetration of bleaching agent into the dental pulp and/or the increase of the pulp temperature. Thus, this study analyzed the effect of an in-office dental bleaching using $35 \%$ hydrogen peroxide and different light sources [halogen light, LED and LED plus laser phototherapy (LPT)] on the pulp vascular permeability that is one of the first signs of inflammation. As expected, the teeth bleached with halogen light, that caused the highest temperature increase (Carrasco et al. 2008; Cobb et al. 2000), presented the more expressive increase in the dental pulp vascular permeability, whereas LED and LED plus LPT caused only small vascular permeability increases.

In order to measure the changes in the vascular permeability in the dental pulp of the teeth subjected to in-office dental bleaching with different light sources, a circulating dye was used (Duval-Araújo et al. 1994). By means of this methodology, it was possible to observe the presence of the dye particles on the dental pulp tissue where alterations of the vascular permeability occurred. The dye run inside the vascular system of the rats and as effect of vascular flow, one hour after the dye application, all dye was excluded of the vascular stream. However, in the tissues where the vascular permeability increased, the passage of the dye through the vascular walls occurred. Then, the dye reached the extra vascular environment and the tissue was permanently stained. Next, the teeth were subjected to diaphanization for revealing the dye at the dental pulp. The amount of dye in the dental pulp tissue indicated the level of edema caused by the in-office dental bleaching procedure applied. In this study, different amount of dye were observed in all the bleached teeth, showing that there was increases in the vascular permeability in all the groups.

The $35 \%$ hydrogen peroxide is one of the more usual active agents used for bleaching. This product has a thermally unstable power oxidative, dissociating in the water, oxygen and free radicals. These low molecular weight radicals are able to increase the porosity of the enamel and degrade the complex organic molecules responsible for the change in tooth color, reducing and eliminating the pigment responsible for darkening the tooth (Goldstein et al. 1989; Goodis et al. 1989; Hanning and Bott 1999; Hanks et al. 1993; Kawamoto and Tsujimoto 2004; Kurgel and Ferreira 2005). According to Hein et al. (2003), there are two tools to accelerate the chemical process of dental bleaching: the thermocatalysis (heat) or photocatalysis (light). Currently, the preferred method of speeding up the bleaching process is photocatalysis with halogen light, LED or laser. However, even photocatalysis can induce increase of intrapulpal temperature with expansion of the liquid inside the dentin tubules resulting in pulp hyperemia and pain (Goodis et al. 1989; Hanning and Bott 1999; Michida et al. 2009). In fact, light accelerates the release of free radicals such as $\mathrm{OH}^{-}$from $\mathrm{H}_{2} \mathrm{O}_{2}$. Part of the energy is converted to heat to degrade the molecules responsible for tooth staining (Buchalla and Attin 2007) and the other part is absorbed, and may cause the intrapulpal temperature increase (Eldeniz et al. 2005).

The increase of the intrapulpal temperature is a cause for concern. The dental pulp is a highly vascularized tissue and its vitality may be compromised by an increase in the temperature through the enamel and dentin (Nyborg and Brännströn 1968). Actually, Zach and Cohen (1965) observed that the increase of the intrapulpal temperature of $3.3{ }^{\circ} \mathrm{C}$ could promote reversible histological changes in this tissue. When the temperature reaches $5.5^{\circ} \mathrm{C}$, it can be threatening to the pulp vitality. Increases of more than $10^{\circ} \mathrm{C}$ induce the periodontal injury, and increases more than $16^{\circ} \mathrm{C}$ can result in complete pulpal necrosis. The halogen light promotes the increase of the intrapulpal temperature (Carrasco et al. 2008). This increase can be higher than those presented by argon laser (Cobb et al. 2000). Aiming at 
reducing the sensitivity symptom new light sources have been introduced at the dental bleaching procedure, such as light emitting diodes (LED) associated or not to low power lasers (Dederich and Bushick 2004; Stabholz et al. 2003). These authors were looking for light sources able to accelerate the bleaching procedure without causing great increases in the intrapulpal temperature. In fact, these authors were right, since later on, in 2008, Carrasco et al. showed in an in vitro study that the halogen light promoted the highest temperature rise in the pulp when coupled with the $35 \%$ hydrogen peroxide (1.41 \pm $0.64{ }^{\circ} \mathrm{C}$ ), while the lowest elevations in the temperature were observed when bleaching was accelerated with the LED light $\left(0.44 \pm 0.11{ }^{\circ} \mathrm{C}\right)$ and the LED associated with the laser $(0.33 \pm$ $0.12^{\circ} \mathrm{C}$ ).

Similar to halogen light, the LED represents a not divergent and coherent source of light. Additionally, it has a thinner emission spectral, a higher output and does not produce heat, which allows its use in the therapies without significant risks. These characteristics validate this light source as an alternative to the conventional lightcuring units (Whelan et al. 2001). Moreover, these light sources are no exothermic and able to reduce the tooth sensitivity (Cohen and Chase 1979; Stabholz et al. 2003).

At the control teeth that were not bleached, there was no stain, showing that the presence of dye at the bleached teeth occurred specifically in the function of the dental bleaching procedure. Then, the vascular permeability increase could occur either due to the metabolites of $35 \%$ hydrogen hydroxide agent breakdown or due to the changes in dental pulp temperature elicited by the light source.

All the bleached samples presented increases in the vascular permeability, independently of the light source used. Then, this result indicated that the bleaching active agent or metabolites of its breakdown could have entered in the dental pulp chamber and elicited the acute inflammation represented by vascular permeability increase. Corroborating with this hypothesis, Dantas et al. (2010), showed increase of cell death in dental pulp fibroblasts cultured in medium conditioned by $35 \%$ hydrogen peroxide.

The source and concentration of the bleaching active agent used in this study was the same for all the bleached samples. Thus, differences in the level of edema observed amongst the experimental groups should be due to the different light sources used. The increase in dental pulp vascular permeability was significantly smaller in the samples treated with LED and/or LED, followed by LPT. As these light sources were not exothermic (Cohen and Chase 1979; Stabholz et al. 2003), the results of this study corroborated with the hypothesis that temperature was a key modulator of the acute inflammation elicited by the in-office dental bleaching. Other important observation in this study was the fact of one session of bleaching using the halogen light led to an increase in the pulp vascular permeability significantly higher than the three sessions of the other bleaching groups. This result confirmed the injury of the high temperature can cause.

There were no differences between the groups treated with LED and LED, followed by LPT. In fact, it was expected to have smaller edema in these groups than in the group of halogen light; however, the LPT was supposed to improve the dental pulp response to the bleaching procedure. This result could be due to the fact that LEDs could have similar phototherapeutic effect on the dental pulp than the low intensity laser. Although, less evidence has been gathered on the biostimulative effect of noncoherent light (LED), some in vitro studies suggested macrophage activation as the first target of this kind of emission (Young et al. 1989). Recent studies have shown that it can exert a laser-like curative effect on skin and mucosal wounds (Whelan et al. 2001). Independently of the number of sessions used in the treatment, the dental bleaching with $35 \%$ hydrogen peroxide agent and LED followed or not by LPT caused lesser increase in the dental pulp vascular permeability than the conventional method using halogen light. These results and the observations of clinical trials of the absence of the sensitivity when dental bleaching was speed up by LEDs (Dederich and Bushick 2004; Stabholz et al. 2003) encouraged that for vital teeth, the dental bleaching using hydrogen peroxide should be done in association with non-exothermic light sources, especially the LEDs. Further studies should be carried out in order to clarify the processes involved in the dental pulp reaction to dental bleaching procedures.

\section{REFERENCES}

Auschill TM, Hellwig E, Schmidale S, Sculean A, Arweiler NB. Efficacy, side-effects and patients' acceptance of different bleaching techniques (OTC, inoffice, at-home). Oper Dent. 2005; 30(2): 156-63. 
Bowles WH, Thompson LR. Vital bleaching: the effects of heat and hydrogen peroxide on pulpal enzymes. $J$ Endod. 1986; 12(3): 108-12.

Buchalla W, Attin T. External bleaching therapy with activation by heat, light or laser: a systematic review. Dent Mater. 2007; 23(5): 586-96.

Carrasco TG, Carrasco-Guerisoli LD, Fröner IC. In vitro study of the pulp chamber temperature rise during lightactivated bleaching. J Appl Oral Sci. 2008; 16(5): 355-9.

Cobb DS, Dederich DN, Gardner TV. In vitro temperature change at the dentin/pulpal interface by using conventional visible light versus argon laser. Lasers Surg Med. 2000; 26(4): 386-97.

Cohen SC. Human pulpal response to bleaching procedures on vital teeth. J Endod. 1979; 5(5):134-8.

Crim GA. Prerestorative bleaching: effect on microleakage of Class V cavities. Quintessence Int. 1992; 23(12): 8235.

Dahl JE, Pallesen U. Tooth bleaching - a critical review of the biological aspects. Crit Rev Oral Biol Med. 2003; 14(4): 292-304.

Dantas CM, Vivan CL, Ferreira LS, Freitas PM, Marques MM. In vitro effect of low intensity laser on the cytotoxicity produced by substances released by bleaching gel. Braz Oral Res. 2010; 24(4): 460-6.

Dederich DN, Bushick RD. Lasers in dentistry: separating science from hype. J Am Dent Assoc. 2004; 135(2): 20412.

Duval-Araujo I, Petroianu A, Simal CJR, Ferraz de Souza IK, Oliveira-Neto JE, Brandão Junior PS. Inibição fagocitéria em fígado, baço e pulmão de ratos. Acta Cir Bras. 1994; 9(4):172-3.

Eldeniz AU, Usumez A, Usumez S, Ozturk N. Pulpal termperature rise during light-activated bleaching. $J$ Biomed Mater Res B Appl Biomater. 2005; 72(2): 254-9.

Goldstein CE, Goldstein RE, Feinman RA, Garber DA. Bleaching vital teeth: state of the art. Quintessence Int. 1989; 20(10): 729-37.

Goodis HE, White JM, Andrews J, Watanabe LG. Measurement of temperature generated by visible-lightcure lamps in an in vitro model. Dent Mater. 1989; 5(4): 230-4.

Hanks CT, Fat JC, Wataha JC, Corcoran JF. Cytotoxicity and dentin permeability of carbamide peroxide and hydrogen peroxide vital bleaching materials, in vitro. $J$ Dent Res. 1993; 72(5): 931-8.

Hannig M, Bott B. In-vitro pulp chamber temperature rise during composite resin polymerization with various light-curing sources. Dent Mater. 1999; 15(4): 275-81.

Hein DK, Ploeger BJ, Hartup JK, Wagstaff RS, Palmer TM, Hansen LD. In-office vital tooth bleaching--what do lights add? Compend Contin Educ Dent. 2003; 24(4A): 340-52

Kawamoto K, Tsujimoto Y. Effects of the hydroxyl radical and hydrogen peroxide on tooth bleaching. J Endod. 2004; 30(1): 45-50.

Kurgel G, Ferreira S. The art and science of tooth whitening. J Mass Dent Soc. 2005; 53(4): 34-7.
Ladalardo TC, Pinheiro A, Campos RA, Brugnera Júnior A, Zanin F, Albernaz PL, Weckx LL. Laser therapy in the treatment of dentine hypersensitivity. Braz Dent J. 2004; 15(2): 144-150.

Michida SM, Passos SP, Marimoto AR, Garakis MC, de Araújo MA. Intrapulpal temperature variation during bleaching with various activation mechanisms. J Appl Oral Sci. 2009; 17(5): 436-9.

Nathanson D, Parra C. Bleaching vital teeth: a review and clinical study. Compendium. 1987; 8(7): 490-2, 494, 496-7.

Nyborg H, Brännström M. Pulp reaction to heat. J Prosthet Dent. 1968; 19(6): 605-12.

Reddy GK. Photobiological basis and clinical role of lowintensity lasers in biology and medicine. J Clin Laser Med Surg. 2004; 22(2): 141-50.

Robertson WD, Melfi RC. Pulpal response to vital bleaching procedures. $J$ Endod. 1980; 6(7): 645-49.

Rotstein I, Dankner E, Goldman A, Heling I, Stabholz A, Zalkind M. Histochemical analysis of dental hard tissues following bleaching. $J$ Endod. 1996; 22(1): 23-5.

Seale NS, McIntosh JE, Taylor NA. Pulpal reaction to bleaching of teeth in dogs. J Dent Res. 1981; 60(5): 94853.

Seale NS, Wilson CFG. Pulpal Response To Bleaching Of Teeth In Dogs. Pediatric Dentistry. 1985; 7(3): 209-214.

Silveira PCL, Streck EL, Pinho RA. Evaluation Of Mitochondrial Respiratory Chain Activity In Wound Healing By Low-Level Laser Therapy. J Photochem Photobiol B. 2007; 86(3): 279-282.

Stabholz A, Zeltser R, Sela M, Peretz B, Moshonov J, Ziskind D, Stabholz A. The use of lasers in dentistry: principles of operation and clinical applications. Compend Contin Educ Dent. 2003; 24(12): 935-48.

Sulieman M. An overview of bleaching techniques: I. History, chemistry, safety and legal aspects. Dent Update. 2004; 31(10): 608-10, 612-4, 616.

Whelan HT, Smits RL Jr, Buchman EV, Whelan NT, Turner SG, Margolis DA, et al. Effect of NASA lightemitting diode irradiation on wound healing. J Clin Laser Med Surg. 2001; 19(6): 305-14.

Young S, Bolton P, Dyson M, Harvey W, Diamantopoulos C. Macrophage responsiveness to light therapy. Lasers Surg Med. 1989; 9(5): 497-505.

Zach L, Cohen G. Pulp response to externally applied heat. Oral Surg Oral Med Oral Pathol. 1965; 19: 515-30.

Zalkind M, Arwazm JR, Goldman A, Rotstein I. Surface morphology changes in human enamel, dentin and cementum following bleaching: a scanning electron microscopy study. Endod Dent Traumatol. 1996; 12(2): $82-8$

Received: November 22, 2010; Revised: March 21, 2011; Accepted: September 27, 2011. 